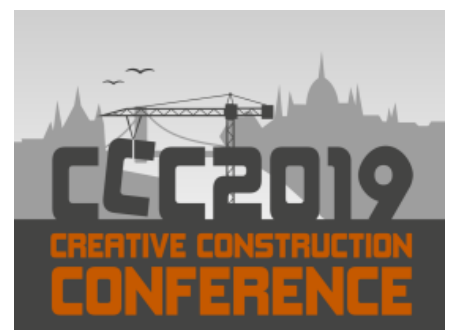

Available online at 2019.creative-construction-conference.com/proceedings/

CCC 2019

Proceedings of the Creative Construction Conference (2019) 078

Edited by: Miroslaw J. Skibniewski \& Miklos Hajdu

https://doi.org/10.3311/CCC2019-078

Creative Construction Conference 2019, CCC 2019, 29 June - 2 July 2019, Budapest, Hungary

\title{
Input for hybrid simulation modelling construction operations
}

\author{
Orsolya Bokor, Laura Florez, Barry Gledson, Allan Osborne \\ Northumbria University, Newcastle upon Tyne, United Kingdom
}

\begin{abstract}
Good pre-construction planning efforts are a vital part of the effective management and delivery of construction projects. In order to prepare more accurate schedules and cost calculations, realistic productivity rates to improve precision are needed. The use of simulation for modelling the elements of construction processes can assist with this aspiration. The application of hybrid simulation approaches is particularly appropriate as they can capture complicated behaviour, uncertainties, and dependencies. This paper discusses the use of one such approach combining discrete-event simulation (DES) and system dynamics (SD) to determine more accurate productivity rates. The DES component models the operations with the workflow of the tasks performed. Its input consists of the task elements with their durations and resource information. The factors that influence the productivity rates are taken into account with the help of the SD component. Input for this part of the model includes the factors as well as considerations of their interrelationships and effects. In this work, a case study of such input data for masonry works - for brick- and blockwork - is presented. It shows the input data and its integration in the DES-SD approach for modellers to determine more realistic productivity rates.
\end{abstract}

(C) 2019 The Authors. Published by Budapest University of Technology and Economics \& Diamond Congress Ltd.

Peer-review under responsibility of the scientific committee of the Creative Construction Conference 2019.

Keywords: discrete-event simulation; labour; masonry; modelling; productivity; simulation; system dynamics.

\section{Introduction}

The construction sector contributes significantly to the world's economy; however, its productivity lags behind other sectors [1]. One of the contributing factors is the present shortage of skilled workers [2]-[4]. Because of this, more careful and accurate planning of construction operations is required. Therefore, it is important to have more realistic productivity rates and resource usage information, which can lead to more precise schedules and cost calculations.

Factors that influence labour productivity rates can be divided into two categories: the first contains those factors that only arise during the construction execution phase (for example, the weather), while the second category, which this research focuses upon, includes those that are known in advance, in the planning phase. For instance, in masonry construction, characteristics of walls and workers belong in the latter group. The specifications of the wall sections can be obtained from design drawings, while the characteristics of the workers are likely known by their supervisors and the contractors.

This paper describes the input data needed for a DES-SD hybrid simulation model that could be used for obtaining better productivity rates. This includes the tasks of block and bricklaying processes for the DES component and the

*Corresponding author: Orsolya Bokor email: orsolya.bokor@ northumbria.ac.uk 
Bokor et al./ Proceedings of the Creative Construction Conference (2019) 078 https://doi.org/10.3311/CCC2019-078

above-mentioned factors for the SD part. Before these are explained in more detail, the next section gives an overview of the studies on factors influencing productivity; it is then shown how simulation can be used in productivity research. Finally, the directions for further development of the model are set.

\section{Factors influencing productivity}

Studies on productivity comprise a substantial portion of construction research [5-6]. Much of these efforts have attempted to identify the factors that influence productivity, especially labour productivity, and group these into various categories. This is usually achieved in two ways. One is a synthesis of existing literature via systematic reviews as done, for instance, by Hasan et. al [2], who listed the factors according to countries and looked for common mentions. Another example is the work of Yi et al. [6], which describes the factors affecting labour productivity at industry, project and activity levels. The other option is to use survey research to uncover and prioritise the most important factors amongst those sourced via existing knowledge. See, for example, Naoum's [7] work, which considers 46 factors grouped into five categories (pre-construction, during construction, management, organisational, motivational and social). Several papers contain lengthy lists of factors, for instance, Dai et al. [8] identified 83 (at project level, grouped into the following categories: supervisor direction, communication, safety, tools and consumables, materials, engineering drawing management, labour, foreman, superintendent, project management, construction equipment), while Tsehayae and Robinson Fayek [9] instead collected 169 factors (grouped according to levels: activity, project, organisational, provincial, national, global). Some studies concentrate on a single country [10]-[13], while others compare and contrast their findings across several countries [14]-[16]. Numerous studies concentrate on the effects of individual factors on productivity such as the influence of project management [17], change orders [18-19], overtime [20], and the introduction of BIM [21].

In cases where surveys are used to determine the most important influencing factors, the results are likely to be affected by the sampling strategies employed and the groups of stakeholders responding. Hasan et al. [2] recommended to include various stakeholders. Kazaz et al. [22] and Dai et al. [8] presented the perspective of the craftsmen, while Alinaitwe et al. [10], Hanna et al. [20], Hickson and Ellis [13], and Proverbs et al. [14] compiled their lists from the contractors' point of view. Additionally, Ailabouni et al. [11] and Tsehayae and Robinson Fayek [9] asked both aforementioned groups: craftsmen and contractors. El-Gohary and Aziz [12] included clients, contractors, and consultants, as well.

There are research projects that focus on one specific work package, with masonry works being one of them. Anand and Ramamurthy [23] measured the productivity rates of the construction of different brick and block sample walls. Due to these observations taking place in a laboratory setting, such results can be used for establishing baseline rates, which are not affected by the factors typically involved in live construction site production. However, the various factors attributed to the workers can still influence the rates.

Thomas and Sakarcan [24] proposed the factor model to calculate productivity rates for masonry works. According to their model, factors (work type, physical elements, construction methods, design requirements, and squad size) were added to the base unit rate as coefficients. The values of the factors were obtained by collecting the daily outputs of several construction projects [24]. In a previous study [25], weather was also accounted for.

Thomas and Zavrski [26] found that the work content (i.e. complexity of design) was an essential influencing factor, as well; thus, a difficulty scale for masonry works was proposed. However, this only works at the project level. Thomas and Sudhakumar [27] suggested a multiple regression model to quantify the effects of influencing factors. Their list of factors included weather parameters, overtime, number of workers, and the aforementioned work content scale. Factors describing the complexity of the work are also part of Sanders and Thomas' [25], Thomas and Zavrski's [26] and Thomas and Sudhakumar's [27] models. However, in those models they characterised the entire project. This study considers the characteristics of the individual wall sections in order to obtain more precise productivity rates.

Olomolaiye [16] studied the effects of motivation and the workers' skills on productivity. He defined skill as a combination of experience, training, and natural ability. The conclusion of his study was that the effect of skills was greater on productivity than that of motivation [16]. Sweis et al. [15] also included skills in their list of productivity 
Bokor et al./ Proceedings of the Creative Construction Conference (2019) 078 https://doi.org/10.3311/CCC2019-078

influencing factors. There skills contained training, work ethics, and motivation. This study also considers the effects of the characteristics of the bricklayers, i.e. their abilities and experience, on labour productivity rates.

Finding the most important factors affecting productivity may be difficult due to many factors acting simultaneously; therefore, defining individual effects may prove challenging. The combined effect of several factors is possibly not equal to the sum of the effect of each one acting alone, owing to their interrelations and dependencies [28]. The use of simulation can be helpful in determining the individual and combined effects of the factors.

\section{Use of simulation for productivity studies}

Simulation can be useful when experimenting on the real-world system would be too expensive, or risky. Therefore, simulation is suitable for analysing construction processes to answer questions about productivity. In the following, examples are shown for the application of basic simulation methods (discrete-event simulation, system dynamics, and agent-based modelling) and hybrid simulation approaches in productivity studies. Hybrid simulation approaches are the combinations of basic simulation methods with each other or with, for instance, fuzzy logic (FL).

Mawdesley and Al-Jibouri [29] attempted to identify the most important factors affecting productivity, their interrelationships and quantified effects through surveys filled in by construction experts. The developed SD model was used to evaluate different strategies and concluded that management should concentrate on planning and control. The concept of Nasirzadeh and Nojedehi's [30] model is similar, as well as the set of project-level influencing factors. Palikhe et al. [31] used SD to determine the most important factors affecting productivity in Nepal. Choi and Bae [32] also applied SD to integrate the effect of various continuous factors into their static estimation model. Olomolaiye [16] used SD to find the critical tasks of the process of bricklaying.

Both Al-Tabbaa and Rustom [33] and Han and Halpin [34] recommended the use of probabilistic over deterministic models and applied DES. The former researchers' model aimed to provide planners with activity and project durations with the help of DES using historic duration data and current site conditions. The latter researchers used DES to increase the amount of data input into a multiple regression model while taking a limited number of influencing factors into account.

Agent-based modelling (ABM) was applied by Watkins et al. [35]to analyse how the efficiency of the workers changes due to site congestion. Two different agents were defined: tasks and workers. The latter ones are characterised by their skill levels.

Alvanchi et al. [36] proposed the combination of DES and SD as the former is suitable for modelling the operation level, while the latter can contain context level variables; thus, allowing the creation of a more accurate model of construction operations. Alzraiee et al. [37] applied the same hybrid simulation approach to get productivity rates. The factors affecting these rates were considered with the SD component.

AbouRizk and Sawhney [38] developed a DES-FL hybrid system which provided the users with beta distribution functions of the activity durations to be applied in schedules. The input data included the selected factors, the likelihood of their occurrence, and their adverse effects. The last two were given in linguistic terms. The estimated minimum and maximum durations also had to be given. The result depended on how accurate information the user could provide.

Nojedehi and Nasirzadeh [39] presented an SD-FL hybrid model, which can be used for determining whether a certain managerial decision will, in fact, increase productivity. The SD part contained the factors influencing productivity, while their effects were quantified with the help of the FL component. Robinson Fayek and Tsehayae [40] recommended the application of hybrid FL approaches for the same reason. However, it was noted that the nature of FL limited the number of influencing factors; therefore, sub-factors were required to be introduced.

Khanzadi et al. [41] suggested an SD-ABM hybrid simulation approach to improve productivity. The SD component contained the influencing factors, while the ABM part had groups of workers as agents and was used to model site congestion. 
Bokor et al./ Proceedings of the Creative Construction Conference (2019) 078

https://doi.org/10.3311/CCC2019-078

Since the objective of this research is to create a model that will provide productivity rates while also considering factors affecting productivity in masonry works, a hybrid simulation approach has been selected. One component is DES because this will give the durations and resource usage data needed. The other is SD for its ability to show the interrelationships of the factors that influence labour productivity. The structure of the model is explained in a previously published paper [42]. The next section describes the input data necessary for each component.

\section{Input for simulation}

\subsection{Input for the SD component}

The SD component of the model comprises of the factors affecting labour productivity rates of masonry works with their interrelations marked and their effects on the productivity rates expressed. It is worth noting that a vast number of factors can be considered; however, this research project concentrates on the information available in the planning phase of a project. At this stage, data on the wall sections and bricklayers are accessible. These can be further divided into sub-groups as shown in Figure 1.

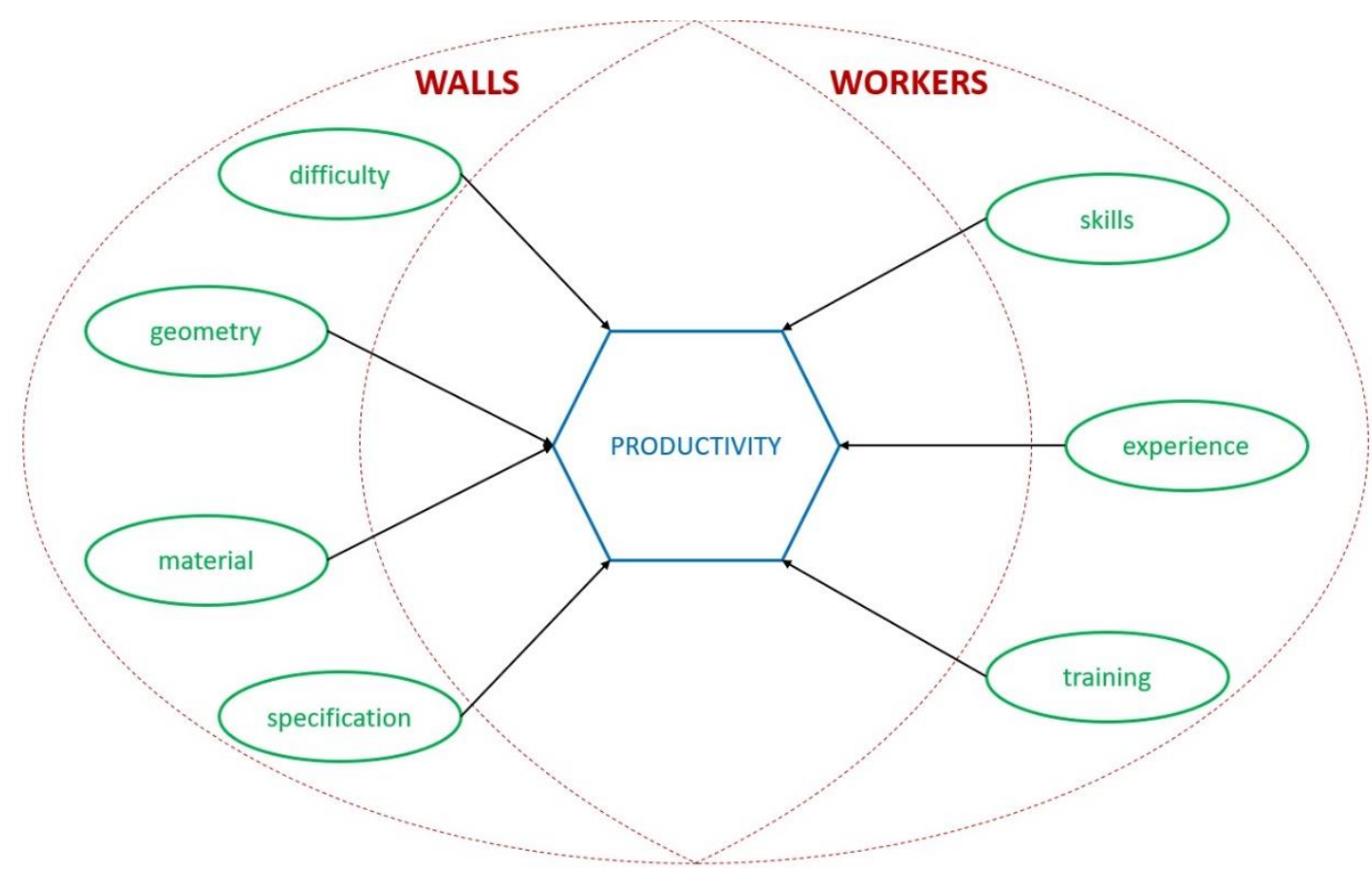

Figure 1. Factors affecting labour productivity rates of masonry works

The sub-groups contain the factors that make up the SD component of the model. For example, the difficulty subgroup includes the factors that determine how complicated it is to construct a given wall section. These are, for instance, the number of openings, cut bricks/blocks, and movement joints. The specification sub-group involves the pointing type and the type of bond required by the design. Figure 2 shows two possible bonding arrangements: the more common and simpler stretcher bond and the more complicated Flemish bond. The construction of simpler walls is generally faster. 
Bokor et al./ Proceedings of the Creative Construction Conference (2019) 078 https://doi.org/10.3311/CCC2019-078
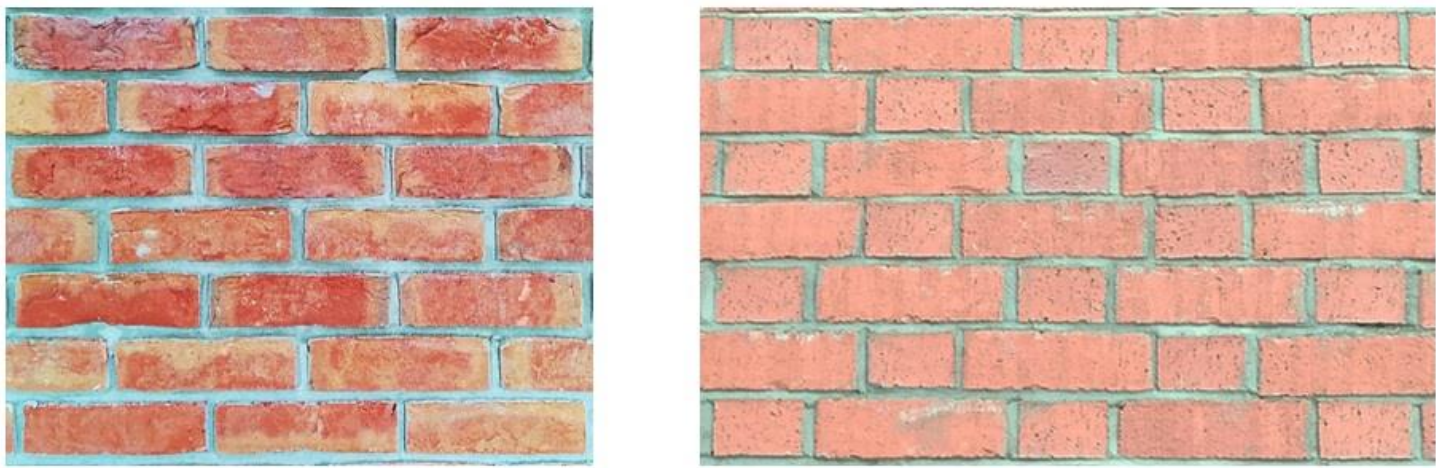

Figure 2. Left: stretcher bond, right: Flemish bond (Orsolya Bokor ${ }^{\complement}$ )

The sub-groups associated with the workers are listed on the right side in Figure 1. For example, the skills sub-group includes factors such as the workers' abilities to work independently, without continuous supervision, and their own technical knowledge.

\subsection{Input for the DES component}

For the DES component of the model the main input are the tasks of the masonry construction process. The workflow of building a block wall is shown in Figure 3. The process starts with the preparation when labourers make ready stacks of blocks, place mortar boards on a number of these, and distribute mortar on them. The next activity is marking the location of the wall section to be built. This is either done by the foreman or by the bricklayers themselves. Laying the base course is crucial. After that the bricklayers build corners at each end of the section, and continuously check the laid blocks with tape measures and spirit levels. The blocks in-between can be laid to the line stretched between the corners. Once they reach scaffolding height, meaning that they can no longer work from the ground, the scaffolding needs to be assembled. Before that, pointing (i.e. tidying up of the joints) is performed and the surface is brushed. After the scaffolding is erected, the work continues in the same way as before until the wall section is finished. When the maximum height is reached, the last step is the final round of pointing.

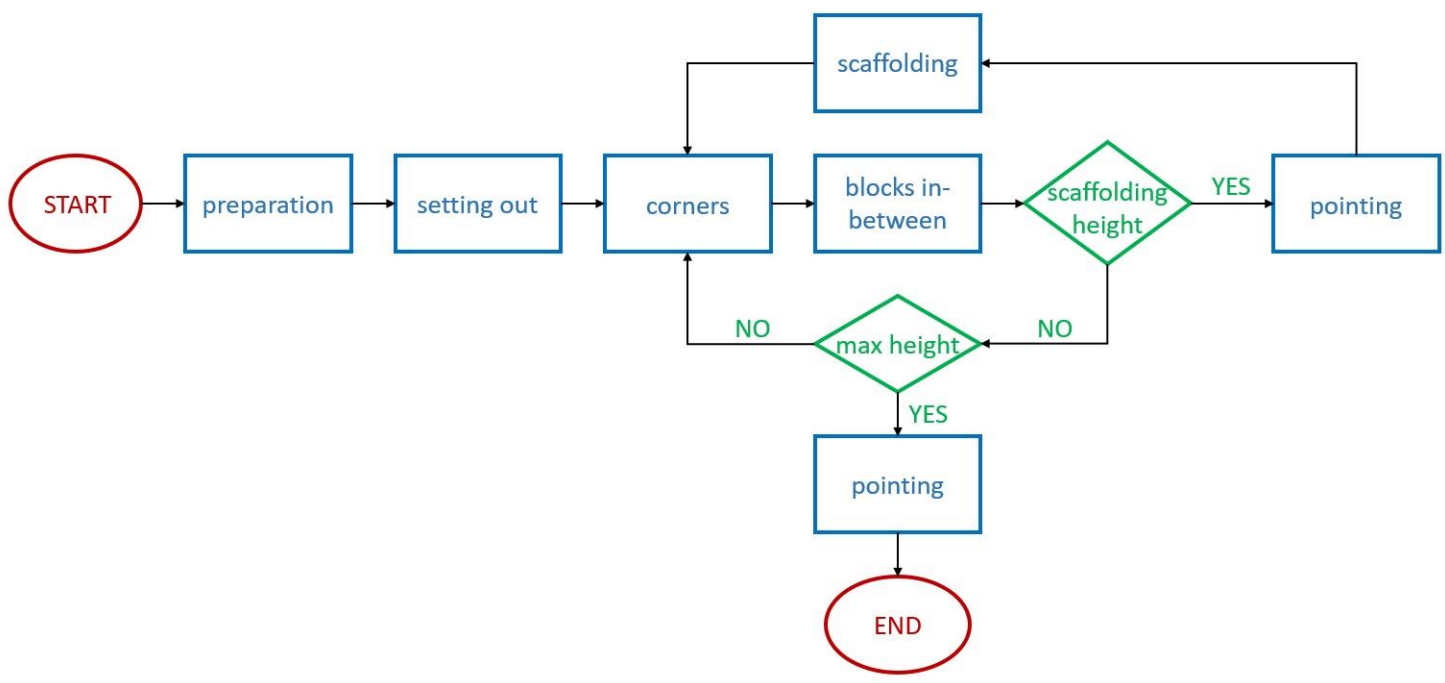

Figure 3. Workflow of blockwork

Another important type of input for the DES component is resource. There are various resources needed for performing the tasks, however, this research focuses on human resources. There are two such labour resources: bricklayers and labourers. Bricklayers start with the setting out, work until the scaffolding needs to be erected by the scaffolders, and 
Bokor et al./ Proceedings of the Creative Construction Conference (2019) 078 https://doi.org/10.3311/CCC2019-078

then return, and stay until the end. Labourers are present throughout the whole process as they are responsible for unloading and distributing materials, which are mostly building blocks and mortar but different sorts of ties and movement joints are also needed. Generally, bricklayers work in squads of two or three depending on the length of the wall section with one labourer helping them.

The final group of input for the DES is the task duration. These are the interface variables providing the connection between the model's two components as their value is affected by the SD part.

\section{Conclusion}

The planning phase of a construction project is important. Accurate productivity rates and resource usage information are essential at this stage. Hybrid simulation approaches can be used for obtaining these. After selecting the most appropriate approach and determining the structure of the model, the input data need to be collected [42]. This is a crucial step as the output will only be as good as the input. To help with this phase of model development, this paper presents the necessary input data for a DES-SD hybrid model which is intended for providing planners with more realistic productivity rates of masonry works.

For the SD component, the list of factors that affect productivity rates needs to be compiled. In this case, it consists of the characteristics of the wall sections and the bricklayers. The interrelationships amongst the factors and their effects are also included in the input data for the SD part. For the DES component representing the workflow, the tasks with their durations and resource requirements comprise the input data. The task durations serve as the interaction points between the two components of the model. Their values are influenced by the SD component.

After the input data are available, the next step is to create the model and run the simulation [42]. Based on initial results, it needs to be refined, then verified and validated with data from real-life projects.

In the future, it needs to be explored whether other hybrid simulation approaches could also be used for the purpose of obtaining more accurate productivity rates. The results of this and the new models should be compared to determine the most suitable one. Moreover, further groups of influencing factors could be input into the model.

\section{References}

[1] F. Barbosa et al., "Reinventing Construction: A Route To Higher Productivity," McKinsey Global Institute, New York, USA, Report. February 2017.

[2] A. Hasan, B. Baroudi, A. Elmualim, and R. Rameezdeen, "Factors affecting construction productivity: a 30 year systematic review," Eng. Constr. Archit. Manag., vol. 25, no. 7, pp. 916-937, 2018. http://dx.doi.org/10.1108/ECAM-02-2017-0035

[3] H. Karimi, T. R. B. Taylor, and P. M. Goodrum, "Analysis of the impact of craft labour availability on North American construction project productivity and schedule performance," Constr. Manag. Econ., vol. 35, no. 6, pp. 368-380, 2017. https://doi.org/10.1080/01446193.2017.1294257

[4] Department for Business, Innovation \& Skills, HM Government, "Construction 2025. Industrial Strategy: Government and industry in partnership," London, UK: HM Government, 2013.

[5] D. A. R. Dolage and P. Chan, "Productivity in Construction-A Critical Review of Research," Eng. J. Inst. Eng. Sri Lanka, vol. 46, no. 4, pp. 31-42, 2013. http://dx.doi.org/10.4038/engineer.v46i4.6808

[6] W. Yi and A. P. C. Chan, "Critical Review of Labor Productivity Research in Construction Journals," J. Manag. Eng., vol. 30, no. 2, pp. 214-225, 2014. https://doi.org/10.1061/(ASCE)ME.1943-5479.0000194

[7] S. G. Naoum, "Factors influencing labor productivity on construction sites: A state-of-the-art literature review and a survey," Int. J. Product. Perform. Manag., vol. 65, no. 3, pp. 401-421, 2016. https://doi.org/10.1108/IJPPM-03-2015-0045

[8] J. Dai, P. M. Goodrum, and W. F. Maloney, "Construction Craft Workers' Perceptions of the Factors Affecting Their Productivity," $J$. Constr. Eng. Manag., vol. 135, no. 3, pp. 217-226, 2009. https://doi.org/10.1061/(ASCE)0733-9364(2009)135:3(217)

[9] A. A. Tsehayae and A. Robinson Fayek, "Identification and comparative analysis of key parameters influencing construction labour productivity in building and industrial projects," Can. J. Civ. Eng., vol. 41, no. 10, pp. 878-891, 2014. http://dx.doi.org/10.1139/cjce-20140031

[10] H. M. Alinaitwe, J. A. Mwakali, and B. Hansson, "Factors affecting the productivity of building craftsmen - Studies of Uganda," J. Civ. Eng. Manag., vol. 13, no. 3, pp. 169-176, 2007. https://doi.org/10.1080/13923730.2007.9636434

[11] N. Ailabouni, N. Painting, and P. Ashton, "Factors affecting employee productivity in the UAE construction industry," in Proceedings 25th Annual ARCOM Conference, 2009, pp. 555-564.

[12] K. M. El-Gohary and R. F. Aziz, "Factors Influencing Construction Labor Productivity in Egypt," J. Manag. Eng., vol. 30, no. 1, pp. 1-10, 2014. https://doi.org/10.1061/(ASCE)ME.1943-5479.0000168 
Bokor et al./ Proceedings of the Creative Construction Conference (2019) 078 https://doi.org/10.3311/CCC2019-078

[13] B. G. Hickson and L. A. Ellis, "Factors affecting Construction Labour Productivity in Trinidad and Tobago," J. Assoc. Prof. Eng. Trinidad Tobago, vol. 42, no. 1, pp. 4-11, 2014.

[14] D. G. Proverbs, G. D. Holt, and P. O. Olomolaiye, "Factors impacting construction project duration: a comparison between France, Germany and the UK," Build. Environ., vol. 34, no. 2, pp. 197-204, 1998. https://doi.org/10.1016/S0360-1323(98)00004-3

[15] G. J. Sweis, R. J. Sweis, A. A. A. Hammad, and H. R. Thomas, "Factors Affecting Baseline Productivity in Masonry Construction: A Comparative Study in the US, UK, and Jordan," Archit. Sci. Rev., vol. 51, no. 2, pp. 146-152, 2008. http://dx.doi.org/10.3763/asre.2008.5118

[16] P. O. Olomolaiye, "An evaluation of bricklayers' motivation and productivity," PhD thesis, Loughborough University, Loughborough, UK, 1988.

[17] P. W. Chan and O. Ejohwomu, "How does project management relate to productivity? A systematic review of published evidence," Association for Project Management, Princes Risborough, UK, Report, 2018.

[18] A. S. Hanna, J. S. Russell, T. W. Gotzion, and E. V. Nordheim, "Impact of Change Orders on Labor Efficiency for Mechanical Construction," J. Constr. Eng. Manag., vol. 125, no. 3, pp. 176-184, 1999. https://doi.org/10.1061/(ASCE)0733-9364(1999)125:3(176)

[19] A. S. Hanna, J. S. Russell, E. V Nordheim, and M. J. Bruggink, "Impact of Change Orders on Labor Efficiency for Electrical Construction," J. Constr. Eng. Manag., vol. 125, no. 4, pp. 224-232, 1999. https://doi.org/10.1061/(ASCE)0733-9364(1999)125:4(224)

[20] A. S. Hanna, C. S. Taylor, and K. T. Sullivan, "Impact of Extended Overtime on Construction Labor Productivity," J. Constr. Eng. Manag., vol. 131, no. 6, pp. 734-739, 2005. https://doi.org/10.1061/(ASCE)0733-9364(2005)131:6(734)

[21] E. A. Poirier, S. Staub-French, and D. Forgues, "Measuring the impact of BIM on labor productivity in a small specialty contracting enterprise through action-research," Autom. Constr., vol. 58, pp. 74-84, 2015. https://doi.org/10.1016/j.autcon.2015.07.002

[22] A. Kazaz, S. Ulubeyli, T. Acikara, and B. Er, "Factors Affecting Labor Productivity: Perspectives of Craft Workers," Procedia Eng., vol. 164, pp. 28-34, 2016. https://doi.org/10.1016/j.proeng.2016.11.588

[23] K. B. Anand and K. Ramamurthy, "Laboratory-Based Productivity Study on Alternative Masonry Systems," J. Constr. Eng. Manag., vol. 129, no. 3, pp. 237-242, 2003. https://doi.org/10.1061/(ASCE)0733-9364(2003)129:3(237)

[24] H. R. Thomas and A. S. Sakarcan, "Forecasting Labor Productivity Using Factor Model," J. Constr. Eng. Manag., vol. 120, no. 1, pp. 228239, 1994. https://doi.org/10.1061/(ASCE)0733-9364(1994)120:1(228)

[25] S. R. Sanders and H. R. Thomas, "Masonry Productivity Forecasting Model," J. Constr. Eng. Manag., vol. 119, no. 1, pp. 163-179, 1993. https://doi.org/10.1061/(ASCE)0733-9364(1993)119:1(163)

[26] H. R. Thomas and I. Završki, "Construction baseline productivity: Theory and practice," J. Constr. Eng. Manag., vol. 125, no. 5, pp. 295303, 1999. https://doi.org/10.1061/(ASCE)0733-9364(1999)125:5(295)

[27] A. V Thomas and J. Sudhakumar, "Modelling Masonry Labour Productivity Using Multiple Regression," in Proceedings 30th Annual ARCOM Conference, 2014, pp. 1345-1354.

[28] R. Horner and B. Talhouni, Effects of Accelerated Working, Delays and Disruption on Labour Productivity. Ascot: The Chartered Institute of Building, 1995.

[29] M. J. Mawdesley and S. Al-Jibouri, "Modelling construction project productivity using systems dynamics approach," Int. J. Product. Perform. Manag., vol. 59, no. 1, pp. 18-36, 2009. https://doi.org/10.1108/17410401011006095

[30] F. Nasirzadeh and P. Nojedehi, "Dynamic modeling of labor productivity in construction projects," Int. J. Proj. Manag., vol. 31, no. 6, pp. 903-911, 2013. https://doi.org/10.1016/j.ijproman.2012.11.003

[31] S. Palikhe, S. Kim, and J. J. Kim, "Critical Success Factors and Dynamic Modeling of Construction Labour Productivity," Int. J. Civ. Eng., vol. 17, no. 3, pp. 427-442, 2019. https://doi.org/10.1007/s40999-018-0282-3

[32] K. S. Choi and D. H. Bae, "Dynamic project performance estimation by combining static estimation models with system dynamics," Inf. Softw. Technol., vol. 51, no. 1, pp. 162-172, 2009. https://doi.org/10.1016/j.infsof.2008.03.001

[33] O. AL-Tabbaa and R. Rustom, "General framework for designing multi-use simulation modules for estimating project durations," Constr. Innov., vol. 11, no. 3, pp. 321-337, 2011. http://dx.doi.org/10.2139/ssrn.2083849

[34] S. Han and D. W. Halpin, "The Use of Simulation for Productivity Estimation based on Multiple Regression Analysis," in Proceedings of the 2005 Winter Simulation Conference, 2005, pp. 1492-1499. https://doi.org/ 10.1145/1162708.1162970

[35] M. Watkins, A. Mukherjee, N. Onder, and K. Mattila, "Using Agent-Based Modeling to Study Construction Labor Productivity as an Emergent Property of Individual and Crew Interactions,” J. Constr. Eng. Manag., vol. 135, no. 7, pp. 657-667, Jul. 2009. https://doi.org/10.1061/(ASCE)CO.1943-7862.0000022

[36] A. Alvanchi, S. H. Lee, and S. AbouRizk, "Modeling Framework and Architecture of Hybrid System Dynamics and Discrete Event Simulation for Construction," Comput. Civ. Infrastruct. Eng., vol. 26, no. 2, pp. 77-91, 2011. https://doi.org/10.1111/j.14678667.2010.00650.x

[37] H. Alzraiee, T. Zayed, and O. Moselhi, "Assessment of construction operations productivity rate as computed by simulation models," in Proceedings of the 2013 Winter Simulation Conference, 2013, pp. 3225-3236. http://dx.doi.org/10.1109/WSC.2013.6721688

[38] S. M. AbouRizk and A. Sawhney, "Subjective and interactive duration estimation," Can. J. Civ. Eng., vol. 20, pp. 457-470, 1993. https://doi.org/10.1139/193-060

[39] P. Nojedehi and F. Nasirzadeh, "A hybrid simulation approach to model and improve construction labor productivity," KSCE J. Civ. Eng., vol. 21, no. 5, pp. 1516-1524, 2017. https://doi.org/10.1007/s12205-016-0278-y

[40] A. Robinson Fayek and A. A. Tsehayae, "Modeling construction labour productivity using fuzzy logic and exploring the use of fuzzy hybrid techniques," in 2012 Annual Meeting of the North American Fuzzy Information Processing Society (NAFIPS), 2012, pp. 1-6. http://dx.doi.org/10.1109/NAFIPS.2012.6291023

[41] M. Khanzadi, F. Nasirzadeh, M. Mir, and P. Nojedehi, "Prediction and improvement of labor productivity using hybrid system dynamics and agent-based modeling approach," Constr. Innov., vol. 18, no. 1, pp. 2-19, 2017. http://dx.doi.org/10.1108/CI-06-2015-0034

[42] O. Bokor, L. Florez, A. Osborne, and B. J. Gledson, "Overview of construction simulation approaches to model construction processes," Organ. Technol. Manag. Constr., vol. 11, pp. 1853-1861, 2019. https://doi.org/10.2478/otmcj-2018-0018 